\title{
Las concepciones epistemológicas, pedagógicas y didácticas del mejor profesorado de las universidades acreditadas en Colombia
}

Primer semestre de $2019 \cdot$ pp. 19-40 Segunda época

N.o 1
The

Epistemological,

Pedagogical and

Didactic Ideas about

the Best Teachers

of Accredited

Universities in

Colombia
A concepções

epistemológicas, pedagógicas e didáticas do melhor professorado das universidades credenciadas na Colômbia

\section{Para citar este artículo}

Marroquín Yerovi, M. y Valverde Riascos, 0. (2019). Las concepciones epistemológicas, pedagógicas y didácticas del mejor profesorado de las universidades acreditadas en Colombia. Folios, 49, 19-40.

doi: 10.17227/Folios.49-9388

Dr. Hna. Marianita Marroquín Yerovi* Orcid: https://orcid.org/0000-0002-7980-0232

Dr. Oscar OImedo Valverde Riascos** Orcid: https://orcid.org/0000-0002-2306-4053

* Docente investigadora de la Universidad Mariana. Doctora en Estudios Sociales y Políticos, Universidad de Valencia, España.

Correo electrónico: hmmarroquin@umariana.edu.co

* Decano de la Facultad de Posgrados y Relaciones Internacionales de la Universidad Mariana. Doctor en Estudios Sociales y Políticos de la Universidad de Valencia, España.

Correo electrónico: ovalverde@umariana.edu.co

Artículo recibido

$22 \cdot 09 \cdot 2017$

Artículo aprobado $20 \cdot 06 \cdot 2018$ 


\title{
Resumen
}

En este artículo se dan a conocer los resultados de una investigación que implicó la vinculación de universidades acreditadas y registradas en la Asociación Colombiana de Universidades (AScúN), sobre el pensamiento del mejor profesor y su quehacer en el aula. La información fue valorada desde cada universidad. En este escenario la información obtenida se clasificó en tres categorías: concepciones epistemológicas empiropositivas, concepciones epistemológicas constructivistas, concepciones de enseñanza empiropositivista, concepciones de enseñanza constructivistas, concepciones de aprendizaje empiropositivistas y concepciones de aprendizaje constructivistas, en un contexto de lo pedagógico y lo didáctico. Se implementó el paradigma plurimetódico, con dominancia cuantitativa y complementariedad cualitativa; el tipo de investigación fue descriptivo comprensivo. Desde lo comprensivo, se complementó el sentido y el significado de las concepciones que subyacen en las prácticas del mejor profesor de los programas acreditados a través de las estrategias de enseñanza, aprendizaje y evaluación. Entre las conclusiones es importante enunciar que mantienen concepciones eclécticas de aprendizaje, enseñanza y ciencia. Respecto de sus prácticas de enseñanza, se evidencian posturas intermedias. Desde lo cualitativo, el significado de las concepciones didácticas desde el aprendizaje y la docencia se ha descubierto que hay un acendrado enfoque constructivista; más, desde el significado de los términos que desde su práctica.

\author{
Palabras clave \\ investigación pedagógica; epistemología; pedagogía
}

\begin{abstract}
This paper shares the results of a research on the thoughts about the best teacher and his/her actions in the classroom, which entailed the participation of universities accredited and registered before the Colombian Association of Universities (ASCÚN). The information was evaluated at each university. In this scenario, the information obtained was classified into three categories: empiropositive epistemological conceptions, constructivist epistemological conceptions, empiropositivist teaching conceptions, constructivist teaching conceptions, in a context of pedagogy and didactics. The polymethodic paradigm was implemented, predominantly quantitative and complementarily qualitative; the research was descriptive and comprehensive in nature. From the comprehensive point of view, the sense and meaning of the conceptions underlying the practice of the best teacher from accredited programs through the teaching, learning and evaluation strategies. One of the most important conclusions is that there are still eclectic conceptions of learning, teaching and science. As for their teaching practices, the study revealed intermediate positions. From a qualitative point of view, the meaning of the didactic conceptions from learning and teaching has been found to have an acute constructivist approach from the meaning of the terms rather than from its practice.

\section{Keywords}

pedagogical research; epistemology; pedagogy
\end{abstract}

\section{Resumo}

Neste artigo apresentamos os resultados de uma pesquisa que envolveu a vinculação de universidades credenciadas e registradas na Associação Colombiana de Universidades (ASCúN), sobre o pensamento do melhor professor e seu trabalho na sala de aula. As informações foram valoradas desde cada universidade. Neste cenário, as informações obtidas foram classificadas em três categorias: concepções epistemológicas empiropostitivistas, concepções epistemológicas construtivistas, concepções de ensino empiropositivista, concepções de ensino construtivistas, em um contexto do pedagógico e o didático. Implementamos o paradigma plurimetódico, com dominância quantitativa e complementaridade qualitativa; o tipo de pesquisa foi descritivo compreensivo. Desde o comprensivo, complementamos o sentido e o significado das concepções que subjazem nas práticas do melhor professor dos programas credenciados através das estratégias de ensino, aprendizagem e avaliação. Entre as conclusões é importante assinalar que e esses professores mantêm concepções ecléticas da aprendizagem, o ensino e a ciência. Ao respeito de suas práticas de ensino, evidenciamos posturas intermédias. Desde o qualitativo, o significado das concepções didáticas desde a aprendizagem e a docência está influenciado por um enfoque construtivista desde o significado desde seus termos mais do que da sua prática.

\section{Palavras-chave}

pesquisa pedagógica; epistemologia; pedagogia 


\section{Introducción}

Las universidades elaboran planes de formación de maestros; sin embargo, estos ameritan una revisión para que se supere la permanencia en el conductismo. Es necesario intentar un cambio, mediante la indagación de aspectos tan importantes como las creencias epistemológicas, pedagógicas y didácticas que poseen los docentes universitarios.

Es notoria la tensión entre tradición e innovación, identificada como la resistencia desde distintos sectores a renovar y actualizar su quehacer docente. Para lograr cambios significativos, es necesario buscar un acercamiento al pensamiento y práctica pedagógica que permita delinear unas pautas de mejoramiento acorde con los resultados. Se ubicó la investigación en ámbitos como lo histórico, al referirse a las concepciones epistemológicas de los educadores, a la luz de teorías de Aristóteles, Santo Tomás de Aquino y Descartes, que contribuyeron a formar ideas y creencias pedagógicas; algunas basadas en contenidos teocéntricos y otras en principios racionales. Luego, se hace mención a la revolución cognitiva que rompe con los esquemas pedagógicos imperantes hasta entonces. Este salto cualitativo abrió espacios para el desarrollo del método científico, creó soluciones a diversos problemas, y así, propició el desarrollo de las ciencias y técnicas modernas, leyes matemáticas y la tecnología.

Respecto del área epistemológica, se menciona a Zuleta (2005), quien eleva su voz para hacer de las dificultades una potencia para mejorar; Rodari (2008), para trascender una acartonada pedagogía de la gramática y recuperar la fantasía; Pennac (1994), quien cuestiona las dinámicas institucionales, que pueden convertirse en espacio de infierno o paraíso. La problemática es grande y obliga también a indagar sobre la concepción de sujeto que plantea Foucault (1982), en su obra Hermenéutica del sujeto, donde delibera sobre el subjetivismo moderno, la institución y la sociedad.

Con relación a lo pedagógico y didáctico, se menciona a Piaget (1896-1980, citado por Pozo, 1997), Ausubel, Novak y Hanesian (1996), Vigotsky (19251934, citado por Pozo, 1997) quien "ha contribuido a una formulación de las relaciones entre aprendizaje y desarrollo mediante su concepto de zona de desarrollo potencial" (p. 208), y de trayectoria pedagógica como: Beltrán (1998); Monereo, Castelló, Clariana, Palma y Pérez (2006), Pozo et al. (2006). Además, en un estudio de caso, titulado "Ser un docente estratégico: cuando cambiar la estrategia no basta", Monereo, Badia, Bilbao, Cerrato y Weise (2006) expresan en uno de los resultados que "evidencian el grado de coherencia existente entre las características de la identidad del profesor y su actuación docente real (self)" (p. 237), lo que constituye un refuerzo al tema central de este artículo. Por su parte Quintero y Torres (citados por González y Ospina, 2014) en el estado del arte de un estudio doctoral entre sus hallazgos expresan:

Las premisas básicas desarrolladas desde el saber pedagógico se sintetizan en el enseñar, aprender y formar desde la propia cotidianidad del docente. Así, la fundamentación pedagógica de los docentes se plantea a partir de sus experiencias significativas, motivaciones, sentimientos, emociones, intuiciones y conceptualizaciones en su labor educativa. (p. 294).

En este contexto, el objetivo general que se planteó fue: explorar lo que se mantiene y se cambia en las concepciones epistemológicas, pedagógicas y didácticas que subyacen en las mejores prácticas pedagógicas del grupo profesoral participante para fortalecer una propuesta de formación permanente. Los objetivos específicos fueron:

- Identificar las concepciones epistemológicas a partir de los principios de actuación relativos a las estrategias de enseñanza y aprendizaje que utiliza el profesorado en el aula de clase.

- Describir las concepciones pedagógicas y didácticas que subyacen en la significación de sus prácticas de enseñanza.

- Relacionar las concepciones epistemológicas, las concepciones pedagógicas y didácticas que se encuentran en los principios de actuación docente. 
- Proponer un plan de mejoramiento de las concepciones epistemológicas, pedagógicas y didácticas del profesorado.

El diseño metodológico fue el plurimetódico, que integra lo cuantitativo y lo cualitativo. Lo primero, porque requiere referir datos concretos acerca de las concepciones epistemológicas, pedagógicas y didácticas. Lo segundo, porque está asociado a la comprensión acerca de la percepción de las concepciones que subyacen en las prácticas pedagógicas que tiene el grupo de profesores participantes de un grupo significativo de universidades acreditadas en Colombia.

\section{Metodología}

La investigación se apoyó en el paradigma plurimetódico: cuantitativo y cualitativo. Los enfoques que se asumieron fueron: a) el empírico analítico, porque se describieron de forma concreta las concepciones epistemológicas, pedagógicas y didácticas de los profesores de universidades acreditadas, y b) el interpretativo, por cuanto permitió la comprensión de las concepciones en las prácticas pedagógicas de los profesores ya mencionados.

Población. Estuvo conformada por 83 universidades inscritas en la Asociación Colombiana de Universidades (ASCÚN), de las cuales 49 son privadas y 34 son públicas.

Muestra. Se optó por un muestreo intencionado y por conveniencia. Intencionado, porque se requirió solicitar a las dependencias responsables de seleccionar un docente mejor evaluado en los programas acreditados de las 32 universidades acreditadas en Colombia.

En el trabajo de campo se logró la participación de 21 universidades, de las cuales, 84,1 \% (18) son instituciones de educación superior privada, $y$ 15,9 \% (3) son instituciones de educación superior pública. De estas instituciones, participaron 116 docentes correspondientes a aquellos con la mejor valoración de desempeño. Dentro del proceso de sistematización se hizo un recuento de 82 profesores con datos completos. La diferencia entre los participantes que enviaron sus datos a la plataforma de la universidad y el número de profesores con datos completos, radica en aquellos que diligenciaron de manera adecuada el cuestionario de tipo Likert y la prueba semántica.

\section{Consolidado de los docentes participantes}

La tabla 1 se refiere a las universidades participantes identificadas con los códigos que la Universidad Mariana dio a cada una por el principio de confidencialidad. Es importante destacar el nivel de estudio, lo cual da a los datos mayor confianza. La mayoría se ubica entre doctor y magíster. Luego se puede apreciar el número de programas acreditados que aportó con el docente mejor evaluado. Esto constituye una satisfacción para la universidad acreditada con un número mayor de programas acreditados y de variadas áreas del conocimiento.

\section{Técnicas e instrumentos de} recolección de información

Se aplicó la escala Likert y una prueba semántica. La escala constó de 50 ítems, agrupados por factores, relativos a las concepciones epistemológicas empiropositivas, concepciones epistemológicas constructivistas, concepciones de enseñanza empiropositivista, concepciones de enseñanza constructivistas, concepciones de aprendizaje empiropositivistas y concepciones de aprendizaje constructivistas (adaptado de Gallego y Pérez, 1999). La prueba semántica incluyó 30 conceptos básicos acerca de epistemología, enseñanza y aprendizaje. La escala Likert cumplió con criterios de calidad, como confiabilidad y validez; la primera, expresada en el alfa de Cronbach de 0,822 para la totalidad de los 50 ítems; mientras que para los cuatro nuevos factores, con un total de 38 ítems, fue de 0,764 (tabla 2). El criterio de validez se cumplió con la de contenido, por cuanto, desde lo teórico, existió una validez racional del conocimiento por cada ítem, la validación de jueces y la validez de respuesta por la población seleccionada; de igual forma, cumplió con la validez de constructo del instrumento, en tanto que por el análisis factorial, se pudo encontrar que existen grupos de variables o categorías con significado común. 
Tabla 1. Consolidado de los docentes participantes

\begin{tabular}{|c|c|c|c|c|c|c|}
\hline \multirow[b]{2}{*}{$\begin{array}{l}\circ \\
\frac{00}{0} \\
.0\end{array}$} & \multirow[b]{2}{*}{ 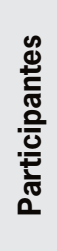 } & \multicolumn{4}{|c|}{ Nivel de estudios } & \multirow[b]{2}{*}{ Programas académicos acreditados } \\
\hline & & 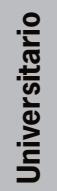 & 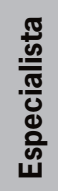 & 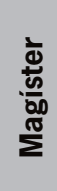 & 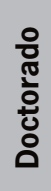 & \\
\hline 25701 & 3 & & & 2 & 1 & Ingeniería de Sistemas e Ingeniería Civil \\
\hline 55701 & 21 & & 2 & 14 & 5 & $\begin{array}{l}\text { Pediatría, Ciencia de la información, Sociología, Medicina, Antropología, Comunicación, } \\
\text { Diseño, Artes Escénicas, Ingeniería Civil, Patología y Arquitectura }\end{array}$ \\
\hline 135701 & 4 & & & 3 & 1 & Ingeniería Financiera, Música, Psicología y Lic. Educación Preescolar \\
\hline 65701 & 2 & & & 2 & & Administración de Empresas y Administración Ambiental \\
\hline 75701 & 1 & 1 & & & & Ingeniería \\
\hline 95701 & 7 & & & 3 & 4 & Enfermería, Psicología, Comunicación Social, Periodismo y Derecho \\
\hline 105701 & 20 & & & 12 & 8 & $\begin{array}{l}\text { Optometría, Ingeniería Ambiental, Economía, Administración de Empresas, Medicina Veterinaria, } \\
\text { Maestría en Docencia, Ingeniería en Automatización, Filosofía y Letras, Arquitectura, Contaduría Pública, } \\
\text { Biología, Negocios y Relaciones Internacionales, Urbanismo y Licenciatura en Educación Religiosa }\end{array}$ \\
\hline 145701 & 8 & & & 2 & 6 & Música, Filosofía, Economía, Historia, Ingeniería Industrial, Ingeniería Mecánica, Ingeniería Civil \\
\hline 155701 & 10 & & 1 & 6 & 3 & $\begin{array}{l}\text { Ingeniería Financiera, Contaduría Pública, Comunicación Gráfica, Ingeniería } \\
\text { Civil, Administración de Empresas e Ingeniería de Sistemas }\end{array}$ \\
\hline 115701 & 1 & & & & 1 & Antropología \\
\hline 15701 & 5 & & & 3 & 2 & Medicina, Ciencias Políticas, Logística, CICS y Logística \\
\hline 175701 & 11 & & & 6 & 3 & $\begin{array}{l}\text { Ingeniería Procesos, Ingeniería de Diseño de Productos, Negocios Internacionales, } \\
\text { Economía, Ingeniería Matemática, Administración de Negocios, Mecánica y Derecho }\end{array}$ \\
\hline 79629256 & 2 & & & 1 & 1 & Contaduría y Comunicación Social \\
\hline 35701 & 4 & & & 4 & & Economía, Comunicación Social y Diseño Gráfico \\
\hline 85701 & 1 & & & & 1 & Ingeniería \\
\hline 125701 & 4 & & & 3 & 1 & Música, Administración de Empresas y Medicina \\
\hline 15719 & 1 & & & & 1 & Comunicación \\
\hline 18570 & 1 & & & 1 & & Administración \\
\hline 2435701 & 9 & 1 & 1 & 6 & 1 & $\begin{array}{l}\text { Ingeniería Industrial, Biología, Ingeniería Electrónica, Tecnología en Sistemas, Ingeniería } \\
\text { de Sistemas, Operación de plantas petroquímicas y Ciencia Política. }\end{array}$ \\
\hline 2435701 & 1 & & & 1 & & Ingeniería de Sistemas \\
\hline
\end{tabular}

Fuente: base de datos del Departamento de Sistemas de la Universidad Mariana.

Tabla 2. Índices de consistencia interna por dimensión y global de escala de las concepciones epistemológicas, pedagógicas y didácticas

\begin{tabular}{|c|c|c|c|}
\hline Factores & No. de ítems & Ítems & $\begin{array}{l}\text { Alfa de } \\
\text { Cronbach }\end{array}$ \\
\hline Concepciones eclécticas de aprendizaje, enseñanza y ciencia & $\begin{array}{l}40,33,5,6,49,38,37,15 \\
14,30,12,29,2,35,47\end{array}$ & 15 & 0,907 \\
\hline Concepciones empiropositivistas de aprendizaje, enseñanza y ciencia & $36,3,20,9,50,28,19,25,43,17,1,32$ & 12 & 0,823 \\
\hline $\begin{array}{l}\text { Concepciones constructivistas acerca de los hombres } \\
\text { y mujeres de ciencia, enseñanza y aprendizaje }\end{array}$ & $4,41,11,10,23,46,16$ & 7 & 0,729 \\
\hline Concepciones constructivistas acerca del mejor profesor y su enseñanza & $21,45,48,24$ & 4 & 0,597 \\
\hline Total escala & Total de los ítems & 38 & 0,764 \\
\hline
\end{tabular}

Fuente: elaboración propia. 
Para la prueba semántica se cumplió con criterios de calidad, como: credibilidad por el juicio de experto, respecto a los conceptos solicitados, mediante observaciones y ajustes a la misma, y retroalimentación por profesores clave que se seleccionaron en la Universidad Mariana.

\section{Resultados}

Una vez aplicada la escala Likert y la prueba semántica, se hizo el respectivo análisis. Los hallazgos o resultados se indicaron de acuerdo con el tratamiento de información señalado en la metodología.

\section{Perspectiva descriptiva de las concepciones}

La perspectiva descriptiva acoge las creencias, o intuiciones conscientes e inconscientes que tiene el profesorado para enseñar de modos determinados (Valverde, 2012). Como teorías implícitas, según Hernández y Sancho (1996), "organizadoras de la práctica que posee cada enseñante y que orientan sus decisiones en la programación, la actuación en la clase o la evaluación y que guían el sentido de su práctica, se las ha denominado concepciones" (p. 168). Pues bien, a partir de los 50 ítems que componen la escala Likert (cuyas opciones de escala van de $1=$ totalmente de acuerdo a $5=$ totalmente en desacuerdo), pueden promover una reflexión acerca de las disposiciones o actitudes conscientes o inconscientes o sobre el uso que hace el grupo profesoral participante de los saberes basados en la experiencia. Para Bain (2007), el mejor profesorado está constituido por "las personas que tienen mucho éxito a la hora de ayudar a sus estudiantes a conseguir resultados de aprendizaje extraordinarios" (p. 13). De igual forma, la expresión saberes basados en la experiencia es una proposición utilizada por Perafán (2015), quien la define como "un conjunto de creencias, principios de actuación, metáforas e imágenes conscientes que los profesores desarrollan durante el ejercicio de su profesión" (p. 24).

Para efectos de la exploración de las tendencias sobre las concepciones epistemológicas, de enseñanza y aprendizaje, estas se promediaron respectivamente con una adaptación, como lo hicieran Gallego y Pérez (1999, p. 85), y las afirmaciones o ítems de la prueba se consideraron como principios de actuación (Perafán, 2015, p. 24) o como estrategias didácticas, término similar al que usó Prieto (2007, p. 171). En la tabla 3 se muestra la agrupación del tipo de concepciones, y cada una de ellas se enumeró según los ítems o estrategias didácticas.

Tabla 3. Agrupaciones de las categorías dadas en la escala Likert

\begin{tabular}{ll}
\hline Epistemología empiropositivista & $2,8,14,19,32,35$ y 47. \\
\hline Epistemología constructivista & $4,10,16,24,29,38$ y 41. \\
\hline Enseñanza empiropositivista & $1,6,9,17,28,30$ y 42. \\
\hline Enseñanza constructivista & $12,21,23,37,45$ y 48. \\
\hline Aprendizaje empiropositivista & $3,20,25,27,36$ y 43. \\
\hline Aprendizaje constructivista & $5,11,15,33,40,46$ y 49. \\
\hline
\end{tabular}

Fuente: elaboración propia. 
De esta escala, se procedió a exponer la información descriptiva referente a las concepciones epistemológica, de enseñanza y aprendizaje, y su análisis comparativo por tipo de universidad; el análisis factorial, es decir, la confianza con que se asume los factores o dimensiones o variables emergentes recurrentes similares a otros estudios y el grado de significación que revelan, teniendo en cuenta este objeto de estudio (Yela, 1997, citado por Valverde, 2012, p. 240).

\section{Concepciones epistemológicas}

Se comprenden como aspectos generales del conocer y el saber. Una vez recogidos y analizados los datos de la escala, se procedió a exponer la información referente a las concepciones que se mantienen como proposiciones en función de: a) las frecuencias obtenidas, la media y la desviación típica para lo empiropositivista y constructivista, y b) el análisis comparativo por tipo de universidad.

Tabla 4. Concepciones epistemológicas empiropositivistas

\begin{tabular}{|c|c|c|c|c|c|c|c|c|c|c|c|}
\hline \multirow[b]{2}{*}{ İtems } & $\begin{array}{l}\text { Totalmente } \\
\text { de acuerdo }\end{array}$ & $\begin{array}{c}\text { De } \\
\text { acuerdo }\end{array}$ & $\begin{array}{c}\text { No sé qué } \\
\text { decir }\end{array}$ & $\begin{array}{c}\text { En } \\
\text { desacuerdo }\end{array}$ & $\begin{array}{l}\text { Totalmente } \\
\text { en }\end{array}$ & \multicolumn{6}{|c|}{ Total } \\
\hline & 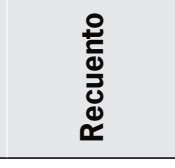 & 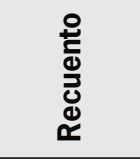 & 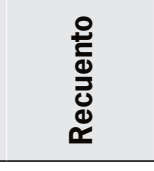 & 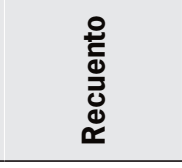 & 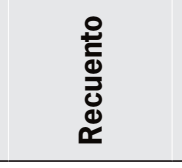 & 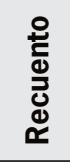 & 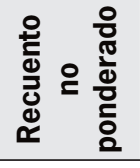 & $\frac{\frac{\pi}{8}}{20}$ & $\begin{array}{l}\frac{\pi}{\pi} \\
\frac{\pi}{\pi} \\
\frac{0}{2} \\
\Sigma\end{array}$ & 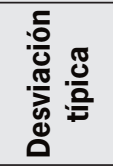 & 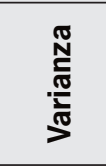 \\
\hline 2 & 13 & 44 & 7 & 15 & 3 & 82 & 82 & 2,402 & 2 & 1,076 & 1,157 \\
\hline 8 & 7 & 33 & 16 & 19 & 7 & 82 & 82 & 2,829 & 3 & 1,142 & 1,304 \\
\hline 14 & 6 & 34 & 23 & 15 & 4 & 82 & 82 & 2,720 & 3 & 1,010 & 1,019 \\
\hline 19 & 3 & 22 & 1 & 33 & 23 & 82 & 82 & 3,622 & 4 & 1,254 & 1,571 \\
\hline 32 & 7 & 30 & 13 & 23 & 9 & 82 & 82 & 2,963 & 3 & 1,201 & 1,443 \\
\hline 35 & 7 & 36 & 12 & 17 & 10 & 82 & 82 & 2,841 & 2 & 1,212 & 1,468 \\
\hline 47 & 4 & 27 & 21 & 25 & 5 & 82 & 82 & 3,000 & 3 & 1,042 & 1,086 \\
\hline
\end{tabular}

Fuente: elaboración propia.

Según la tabla 4, son cinco las creencias relativas a los experimentos, a las teorías científicas, al conocimiento científico y a las teorías en general, que tienen una media con valor mayor a 2 o igual a 3 , lo que indica que hay una mayor inseguridad por parte del profesorado en rechazar o aceptar las ideas empiropositivistas en la enseñanza y aprendizaje de las ciencias. De igual manera, se muestra una tendencia muy baja a aceptar (media de 2) las posiciones empiropositivistas acerca de cómo las teorías de las ciencias son obtenidas a partir de observaciones cuidadosas del mundo. Sin embargo, con una media con valor igual a 4 (en desacuerdo), se rechaza la idea empiropositivista de que el progreso científico se caracteriza por la continuidad y conservación de las ideas sobre el mundo. 
Tabla 5. Concepciones epistemológicas constructivistas

\begin{tabular}{|c|c|c|c|c|c|c|c|c|c|c|}
\hline \multirow[b]{2}{*}{ İtems } & $\begin{array}{l}\text { Totalmente } \\
\text { de acuerdo }\end{array}$ & $\begin{array}{c}\text { De } \\
\text { acuerdo }\end{array}$ & $\begin{array}{c}\text { No sé } \\
\text { qué decir }\end{array}$ & $\begin{array}{c}\text { En } \\
\text { desacuerdo }\end{array}$ & $\begin{array}{c}\text { Totalmente } \\
\text { en } \\
\text { desacuerdo }\end{array}$ & \multicolumn{5}{|c|}{ Total } \\
\hline & 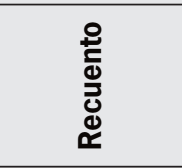 & 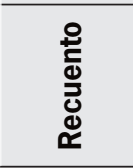 & 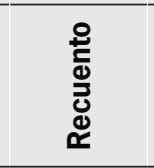 & 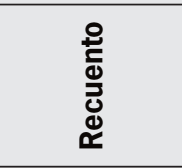 & 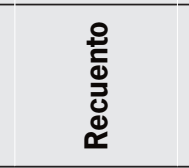 & 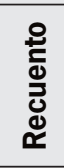 & $\frac{\frac{\pi}{\pi}}{\stackrel{0}{\Sigma}}$ & 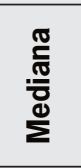 & 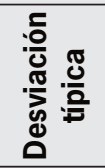 & 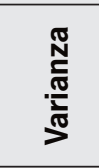 \\
\hline 4 & 16 & 44 & 11 & 11 & 0 & 82 & 2,207 & 2 & 0,913 & 0,833 \\
\hline 10 & 10 & 33 & 21 & 17 & 1 & 82 & 2,585 & 2 & 0,993 & 0,986 \\
\hline 16 & 9 & 22 & 15 & 30 & 6 & 82 & 3,024 & 3 & 1,176 & 1,382 \\
\hline 24 & 9 & 32 & 28 & 10 & 3 & 82 & 2,585 & 3 & 0,968 & 0,937 \\
\hline 29 & 12 & 47 & 8 & 13 & 2 & 82 & 2,341 & 2 & 0,997 & 0,993 \\
\hline 38 & 17 & 26 & 17 & 18 & 4 & 82 & 2,585 & 2 & 1,186 & 1,406 \\
\hline 41 & 12 & 50 & 10 & 8 & 2 & 82 & 2,244 & 2 & 0,910 & 0,829 \\
\hline
\end{tabular}

Fuente: elaboración propia.

En la tabla 5 se puede analizar (valores resaltados) cómo los seis ítems que forman parte de las concepciones epistemológicas constructivistas, tienen puntuaciones entre 2 (de acuerdo) y 3 (no sé qué decir). Las creencias, disposiciones o tendencias del mejor profesorado universitario tienen inseguridad en aceptar las epistemológicas constructivistas respecto a la construcción del conocimiento de la realidad. Sin embargo, no saben qué decir acerca de la idea constructivista de que lo que caracteriza a la ciencia no son los hechos sino sus teorías sobre estos.

\section{Concepciones de enseñanza}

Se comprenden como aspectos generales de la teoría de la enseñanza, expresadas en lo que sabe y conoce el docente de la didáctica en general.

Tabla 6. Concepciones de enseñanza empiropositivista

\begin{tabular}{|c|c|c|c|c|c|c|c|c|c|c|}
\hline \multirow[b]{2}{*}{ Ítem } & $\begin{array}{l}\text { Totalmente } \\
\text { de acuerdo }\end{array}$ & $\begin{array}{c}\text { De } \\
\text { acuerdo }\end{array}$ & $\begin{array}{l}\text { No sé } \\
\text { qué } \\
\text { decir }\end{array}$ & $\begin{array}{c}\text { En } \\
\text { desacuerdo }\end{array}$ & $\begin{array}{c}\text { Totalmente en } \\
\text { desacuerdo }\end{array}$ & \multicolumn{5}{|c|}{ Total } \\
\hline & 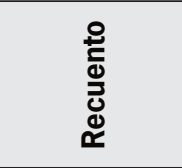 & 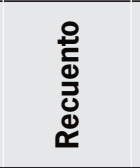 & 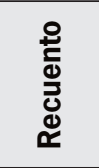 & 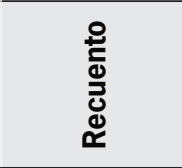 & 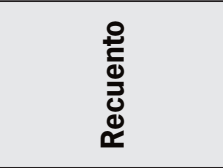 & 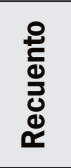 & $\begin{array}{l}\frac{\pi}{\sigma} \\
\sum \\
\Sigma\end{array}$ & 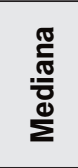 & 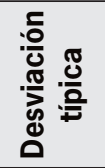 & 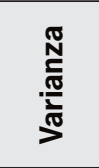 \\
\hline 1 & 3 & 17 & 6 & 41 & 15 & 82 & 3,585 & 4 & 1,122 & 1,258 \\
\hline 6 & 18 & 40 & 5 & 15 & 4 & 82 & 2,354 & 2 & 1,159 & 1,343 \\
\hline 9 & 7 & 15 & 12 & 38 & 10 & 82 & 3,354 & 4 & 1,169 & 1,367 \\
\hline 17 & 10 & 13 & 1 & 31 & 27 & 82 & 3,634 & 4 & 1,401 & 1,963 \\
\hline 28 & 2 & 24 & 13 & 30 & 13 & 82 & 3,341 & 4 & 1,136 & 1,289 \\
\hline 30 & 25 & 41 & 2 & 11 & 3 & 82 & 2,098 & 2 & 1,096 & 1,200 \\
\hline 42 & 7 & 30 & 17 & 26 & 2 & 82 & 2,829 & 3 & 1,052 & 1,106 \\
\hline
\end{tabular}

Fuente: elaboración propia. 
En la tabla 6 se puede observar que son cinco las creencias relativas a la enseñanza empiropositivista: a la transmisión de la enseñanza, a explicar y reforzar en clase, a que se enseñan sin conocimientos previos, a que enseñar es asimilar a la enseñanza de las ciencias naturales o sociales, las explicaciones y los experimentos buscan demostrar los logros teóricos elaborados. Estas alcanzan una media que está entre un valor aproximado o igual o mayor a
3 (no sé qué decir), lo cual indica una inseguridad del profesorado, en rechazar o aceptar las ideas de enseñanza empiropositivistas de las ciencias. De igual manera, se muestra una tendencia muy baja a aceptar (media de 2) las posiciones de enseñanza empiropositivistas de que, para enseñar, el profesor hace que los estudiantes observen y expliquen algunos fenómenos y saquen conclusiones, y que enseñar es lograr que los alumnos descubran el conocimiento.

Tabla 7. Concepciones de enseñanza constructivista

\begin{tabular}{|c|c|c|c|c|c|c|c|c|c|c|}
\hline \multirow[b]{2}{*}{ Ítems } & \multirow{2}{*}{ 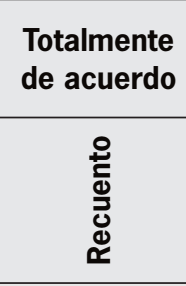 } & \multirow{2}{*}{ 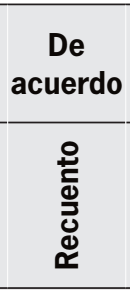 } & \multirow{2}{*}{ 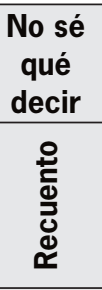 } & \multirow{2}{*}{ 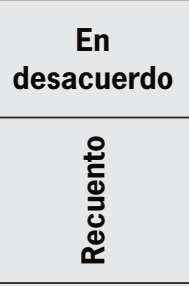 } & \multirow{2}{*}{ 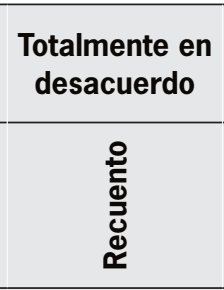 } & \multicolumn{5}{|c|}{ Total } \\
\hline & & & & & & 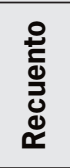 & $\begin{array}{l}\frac{\pi}{\bar{\sigma}} \\
\sum\end{array}$ & 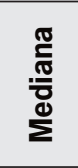 & 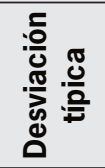 & 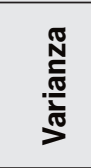 \\
\hline 12 & 30 & 43 & 1 & 5 & 3 & 82 & 1,878 & 2 & 0,974 & 0,948 \\
\hline 21 & 31 & 33 & 9 & 5 & 4 & 82 & 2,000 & 2 & 1,089 & 1,185 \\
\hline 23 & 25 & 42 & 6 & 7 & 2 & 82 & 2,012 & 2 & 0,975 & 0,950 \\
\hline 37 & 18 & 38 & 9 & 12 & 5 & 82 & 2,366 & 2 & 1,160 & 1,346 \\
\hline 45 & 28 & 35 & 5 & 9 & 5 & 82 & 2,122 & 2 & 1,180 & 1,392 \\
\hline 48 & 3 & 41 & 12 & 20 & 6 & 82 & 2,817 & 2 & 1,079 & 1,164 \\
\hline
\end{tabular}

Fuente: elaboración propia.

En la tabla 7 se puede analizar (valores resaltados) cómo los cinco ítems que se incluyen. Tienen puntuaciones de 2 (de acuerdo), que implica que entre las creencias o tendencias del profesorado universitario, se acepta la enseñanza constructivista respecto a que se debe procurar que el estudiante contraste los significados elaborados; que al enseñar, haya un cambio conceptual, metodológico, actitudinal y axiológico. Sin embargo, existe inseguridad acerca de la idea constructivista de que, al enseñar, el profesor busca que sus estudiantes construyan teorías que luego deben demostrar.

\section{Concepciones de aprendizaje}

Implican aspectos generales de la teoría del aprendizaje expresadas en lo que sabe y conoce sobre qué es el aprendizaje y cómo se aprende en el contexto de aula. Sin embargo, se destacan concepciones o proposiciones o saberes problémicos significativos propios del aprendizaje empiropositivista y constructivista. 
Universidad Pedagógica Nacional

Facultad de Humanidades

Tabla 8. Concepciones del aprendizaje empiropositivista

\begin{tabular}{|c|c|c|c|c|c|c|c|c|c|c|}
\hline \multirow[b]{2}{*}{ Ítem } & \multirow{2}{*}{ 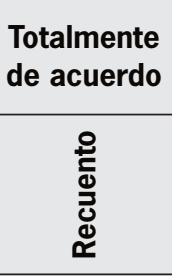 } & \multirow{2}{*}{ 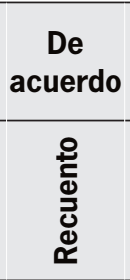 } & \multirow{2}{*}{ 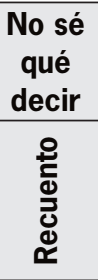 } & \multirow{2}{*}{ 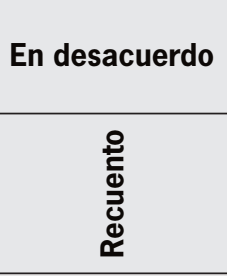 } & \multirow{2}{*}{ 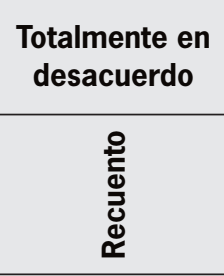 } & \multicolumn{5}{|c|}{ Total } \\
\hline & & & & & & 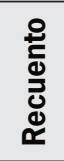 & $\begin{array}{l}\frac{\pi}{\bar{\sigma}} \\
\sum^{\frac{\pi}{\Sigma}}\end{array}$ & 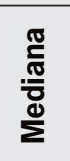 & 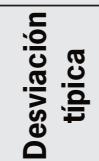 & $\begin{array}{l}\frac{7}{\pi} \\
\substack{\frac{\pi}{\pi} \\
\frac{\pi}{2}}\end{array}$ \\
\hline 3 & 2 & 14 & 5 & 33 & 28 & 82 & 3,866 & 4 & 1,141 & 1,303 \\
\hline 20 & 3 & 11 & 4 & 30 & 34 & 82 & 3,988 & 4 & 1,160 & 1,346 \\
\hline 25 & 10 & 5 & 2 & 29 & 36 & 82 & 3,927 & 4 & 1,350 & 1,822 \\
\hline 27 & 12 & 27 & 8 & 24 & 11 & 82 & 2,939 & 3 & 1,327 & 1,762 \\
\hline 36 & 8 & 9 & 1 & 37 & 27 & 82 & 3,805 & 4 & 1,281 & 1,640 \\
\hline 43 & 5 & 16 & 8 & 29 & 24 & 82 & 3,622 & 4 & 1,263 & 1,596 \\
\hline
\end{tabular}

Fuente: elaboración propia.

Según la tabla 8 , son cinco las creencias o tendencias relativas en que el estudiante demuestra el aprendizaje por repetición; a que el aprendizaje es una acumulación de información; a que aprender es aceptar verdades absolutas. Creencias que alcanzan una media con un valor aproximado a 4 (en desacuerdo), indicando que el profesorado rechaza estas ideas de aprendizaje empiropositivistas de las ciencias. De igual manera, se muestra una tendencia muy baja de inseguridad (media de 3) hacia la creencia o posición del aprendizaje empiropositivista de que, aprender significativamente no implica cambiar lo que ya se sabe.

Tabla 9. Concepciones del aprendizaje constructivista

\begin{tabular}{|c|c|c|c|c|c|c|c|c|c|c|c|}
\hline \multirow[b]{2}{*}{ İtem } & \multirow{2}{*}{ 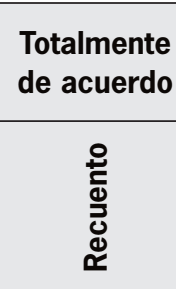 } & \multirow{2}{*}{ 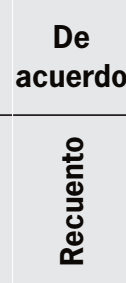 } & \multirow{2}{*}{ 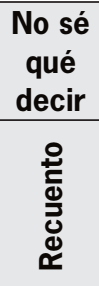 } & \multirow{2}{*}{ 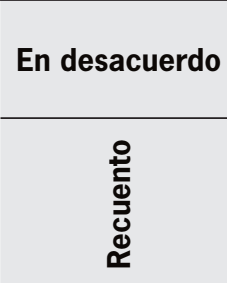 } & \multirow{2}{*}{ 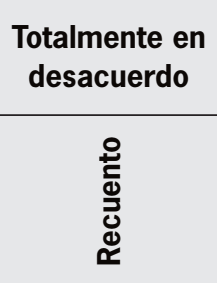 } & \multicolumn{6}{|c|}{ Total } \\
\hline & & & & & & 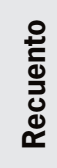 & 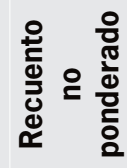 & $\begin{array}{l}\frac{\pi}{\bar{\sigma}} \\
\sum \\
\Sigma\end{array}$ & 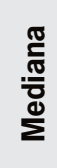 & 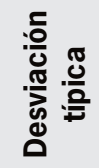 & 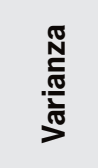 \\
\hline 5 & 23 & 38 & 6 & 8 & 7 & 82 & 82 & 2,244 & 2 & 1,213 & 1,471 \\
\hline 11 & 16 & 37 & 5 & 19 & 5 & 82 & 82 & 2,512 & 2 & 1,220 & 1,488 \\
\hline 15 & 11 & 48 & 10 & 9 & 4 & 82 & 82 & 2,354 & 2 & 1,011 & 1,022 \\
\hline 33 & 23 & 43 & 5 & 7 & 4 & 82 & 82 & 2,098 & 2 & 1,061 & 1,126 \\
\hline 40 & 29 & 37 & 3 & 9 & 4 & 82 & 82 & 2,049 & 2 & 1,132 & 1,282 \\
\hline 46 & 20 & 46 & 5 & 8 & 3 & 82 & 82 & 2,122 & 2 & 1,011 & 1,022 \\
\hline 49 & 19 & 43 & 7 & 8 & 5 & 82 & 82 & 2,232 & 2 & 1,103 & 1,217 \\
\hline
\end{tabular}


En la tabla 9, se observa (valores resaltados) cómo la gran mayoría de los ítems tienen puntuaciones de 2 (de acuerdo), lo que implica que las creencias del grupo profesoral participante tienden hacia un aprendizaje constructivista, pues todo aprendizaje lo es, en la medida en que los estudiantes elaboren el significado; que aprender es transformar aquellas explicaciones que ya se posee; que en el proceso de aprendizaje el estudiante construye conscientemente nuevos significados; que el aprendizaje es acompañado y en permanente autoevaluación, y que el estudiante utiliza su pensamiento autónomo y divergente en la mejora de sus aprendizajes. Sin embargo, hay cierta inseguridad acerca de la idea de aprendizaje constructivista de que los estudiantes aprenden a partir de lo que ya saben.

\section{Análisis de correlaciones en los factores y lo que cambia o se mantiene en las concepciones del mejor profesor universitario}

Se realizó un análisis factorial, es decir, que las respuestas acerca de las concepciones epistemológicas, pedagógicas y didácticas del profesorado se pueden encontrar en grupos de variables o categorías con significado común, con lo cual se reduce el número de dimensiones necesarias para explicar las respuestas del profesorado, así como también, encontrar los grupos de profesores homogéneos cuyos ítems se correlacionan entre sí y que inicialmente fueron independientes de otros. Dicho análisis se hizo a partir de la prueba de кмо у Bartlett con un valor de 0,735 , y el método de extracción de componentes principales VARIMAX, eliminando aquellos factores que explicaban menos de un $5 \%$ de la varianza; se obtuvieron cuatro factores que explican un total del $47,318 \%$ de la varianza. En la tabla 10 se incluye el porcentaje de varianza explicado por cada uno de los cuatro factores y el porcentaje de varianza acumulada.

Tabla 10. Porcentaje de varianza explicada

\begin{tabular}{c|c|c}
\hline Factores & \% de la varianza & $\begin{array}{c}\text { \% de varianza } \\
\text { acumulada }\end{array}$ \\
\hline 1 & 17,873 & 17,873 \\
\hline 2 & 11,690 & 29,563 \\
\hline 3 & 10,790 & 40,354 \\
\hline 4 & 6,964 & 47,318 \\
\hline
\end{tabular}

Fuente: elaboración propia.

A continuación, se exponen los factores, haciendo constar los elementos que componen y la carga factorial de cada uno, teniendo en cuenta que, para la descripción e interpretación, se han tomado aquellos con una carga factorial igual o superior a 0,40 .

Tabla 11. Factor 1. Concepciones eclécticas del aprendizaje, la enseñanza y la ciencia

\begin{tabular}{clc}
\hline İtem (15) & Estrategias didácticas o principios de actuación & $\begin{array}{c}\text { Carga } \\
\text { factorial }\end{array}$ \\
\hline 40 & $\begin{array}{l}\text { El aprendizaje es un proceso acompañado y en permanente autoevaluación, } \\
\text { que se apoya en sus fortalezas y corrige errores. }\end{array}$ & 0,760 \\
\hline 33 & $\begin{array}{l}\text { En el proceso de aprendizaje, los estudiantes construyen, } \\
\text { conscientemente, nuevos significados. }\end{array}$ & 0,755 \\
\hline 5 & Todo aprendizaje lo es, en la medida en que los alumnos elaboran nuevos significados. & 0,718 \\
\hline 49 & $\begin{array}{l}\text { Para enseñar, el profesor hace que los estudiantes observen y } \\
\text { expliquen algunos fenómenos y saquen conclusiones. }\end{array}$ & 0,704 \\
\hline
\end{tabular}


Universidad Pedagógica Nacional

Facultad de Humanidades

\begin{tabular}{|c|c|c|}
\hline Ítem (15) & Estrategias didácticas o principios de actuación & $\begin{array}{l}\text { Carga } \\
\text { factorial }\end{array}$ \\
\hline 38 & Las ciencias son una tradición cambiante de lenguajes y metodologías. & 0,675 \\
\hline 37 & $\begin{array}{l}\text { Enseñar es desarrollar en los estudiantes la conciencia } \\
\text { de que los conceptos científicos cambian. }\end{array}$ & 0,602 \\
\hline 15 & $\begin{array}{l}\text { Aprender es transformar aquellas explicaciones que ya se posee, sobre } \\
\text { los fenómenos acerca de los cuales trata el contenido de la clase. }\end{array}$ & 0,600 \\
\hline 14 & Las teorías científicas son frutos de procesos deductivos inductivos. & 0,578 \\
\hline 30 & Enseñar es lograr que los alumnos descubran el conocimiento. & 0,577 \\
\hline 12 & $\begin{array}{l}\text { Uno de los aspectos de la enseñanza es procurar que los estudiantes contrasten, } \\
\text { mediante observaciones y explicaciones, los significados que han elaborado. }\end{array}$ & 0,544 \\
\hline 29 & Los conceptos de la ciencia son construcciones elaboradas a partir de la realidad. & 0,520 \\
\hline 2 & Las teorías de las ciencias son obtenidas a partir de observaciones cuidadosas del mundo. & 0,490 \\
\hline 35 & La tarea de la investigación científica es descubrir cómo funciona el mundo verdaderamente. & 0,454 \\
\hline 47 & A las teorías se llega por descubrimiento. & 0,382 \\
\hline
\end{tabular}

Fuente: elaboración propia.

Los quince ítems que forman el factor 1 (tabla 11), de forma directa o indirecta, intentan conciliar pensamientos y acciones que se derivan en elementos procedentes de ideas o postulados diversos, ya sean constructivistas o empiropositivistas, denominado: concepciones eclécticas del aprendizaje, la enseñanza y la ciencia. En primera instancia, se resaltan los coeficientes de correlación estadísticamente significativos, cuando se determina la concepción del aprendizaje constructivista entendida como proceso donde el estudiante construye y elabora nuevos significados, acompañado y en permanente autoevaluación, reconociendo sus fortalezas y corrigiendo errores, y poniendo en juego el pensamiento autónomo y divergente para aprender a transformar aquellas explicaciones que ya posee. En una segunda instancia, con correlaciones moderadas, enfatizan que la enseñanza constructivista debe desarrollar en los estudiantes conciencia en torno a que los conceptos científicos cambian y contrastan, mediante observaciones y explicaciones, los significados que han elaborado. En tercera instancia, con correlaciones bajas, se argumenta que las ciencias son tradiciones cambiantes de lenguajes y metodologías, y que los conceptos de las ciencias son elaboraciones efectuadas de la realidad. 
Tabla 12. Factor 2. Concepciones empiropositivistas del aprendizaje, la enseñanza y la ciencia

\begin{tabular}{|c|c|c|}
\hline Ítem (12) & Estrategias didácticas o principios de actuación & $\begin{array}{c}\text { Carga } \\
\text { factorial }\end{array}$ \\
\hline 36 & $\begin{array}{l}\text { El estudiante demuestra que ha aprendido cuando } \\
\text { reproduce lo que el profesor le ha enseñado. }\end{array}$ & 0,749 \\
\hline 3 & Los estudiantes demuestran su aprendizaje cuando repiten lo expuesto en clase. & 0,682 \\
\hline 20 & El aprendizaje es siempre una acumulación de información. & 0,668 \\
\hline 9 & Lo más importante para el profesor es hacer explicaciones y refuerzos en clase. & 0,558 \\
\hline 50 & Los hombres y mujeres de ciencia se dedican a repetir lo validado por la tradición. & 0,523 \\
\hline 28 & Enseñar es procurar que el alumno asimile lo expuesto por el profesor. & 0,514 \\
\hline 19 & $\begin{array}{c}\text { El progreso científico se caracteriza por la continuidad y } \\
\text { conservación de las ideas sobre el mundo. }\end{array}$ & 0,510 \\
\hline 25 & Aprender es aceptar una serie de verdades absolutas. & 0,485 \\
\hline 43 & El aprendizaje es independiente de la enseñanza. & 0,453 \\
\hline 17 & Para enseñar no es indispensable lo que los alumnos ya saben o conocen previamente. & 0,451 \\
\hline 1 & Enseñar es transmitir conocimientos a los estudiantes. & 0,424 \\
\hline 32 & El conocimiento científico es una permanente acumulación de principios, leyes y teorías. & 0,391 \\
\hline
\end{tabular}

Fuente: elaboración propia.

En este caso, las correlaciones más significativas están en el aprendizaje empiropositivista, caracterizado porque el estudiante reproduce lo enseñado por el profesor. De forma común se encuentran correlaciones moderadas de que la enseñanza empiropositivista. Además, se caracterizan porque se dedican a repetir lo validado por la ciencia; el progreso científico por la continuidad y conservación de las ideas sobre el mundo y el conocimiento científico, por la acumulación de principios, leyes y teorías. 
Universidad Pedagógica Nacional

Facultad de Humanidades

Tabla 13. Factor 3. Concepciones constructivistas acerca de los hombres y mujeres de ciencias, de la enseñanza y aprendizaje

\begin{tabular}{clc}
\hline İtem (8) & Estrategias didácticas o principios de actuación & $\begin{array}{c}\text { Carga } \\
\text { factorial }\end{array}$ \\
\hline 4 & La tarea de los hombres de ciencias es construir conocimiento sobre la realidad. & 0,671 \\
\hline 41 & Los hombres y mujeres de ciencias se dedican a la construcción de teorías sobre la realidad. & 0,669 \\
\hline 11 & Los estudiantes aprenden a partir de lo que ya saben. & 0,630 \\
\hline 10 & Las teorías de las ciencias son tramas significativas de conceptos. & 0,601 \\
\hline 23 & $\begin{array}{l}\text { Enseñar es generar el ámbito pedagógico y didáctico con } \\
\text { miras a lograr unas experiencias de aprendizaje. }\end{array}$ & 0,586 \\
\hline 46 & $\begin{array}{l}\text { Los experimentos son construcciones instrumentales que proceden a las teorías. } \\
\text { nuevas propuestas temáticas de sus profesores. }\end{array}$ & 0,535 \\
\hline 16 & Lo que caracteriza a la ciencia no son los hechos sino sus teorías sobre los mismos. & 0,532 \\
\hline
\end{tabular}

Fuente: elaboración propia.

En este factor, siete ítems guardan una correlación moderada y están referidos a ideas o teorías personales o implícitas que, el mejor profesorado de las universidades participantes posee, entre otros aspectos, que son considerados esenciales desde las ideas epistemológicas constructivistas. Sin embargo, con una correlación baja, la concepción epistemológica empiropositivista reitera en que el experimento es una construcción técnico instrumental. Lo que hace que sus concepciones no sean estrictamente constructivistas y exista pensamientos o acciones que se deriven de variadas tendencias.

Tabla 14. Factor 4. Las concepciones constructivistas acerca del profesor y su enseñanza

\begin{tabular}{clc}
\hline Ítem (6) & \multicolumn{1}{c}{ Estrategias didácticas o principios de actuación } & $\begin{array}{c}\text { Carga } \\
\text { factorial }\end{array}$ \\
\hline 21 & $\begin{array}{l}\text { Al enseñar, el profesor debe perseguir un cambio conceptual, } \\
\text { metodológico, actitudinal y axiológico. }\end{array}$ & 0,681 \\
\hline 45 & $\begin{array}{l}\text { El mejor profesor es aquel que logra un cambio conceptual, } \\
\text { metodológico, actitudinal y axiológico en sus estudiantes. }\end{array}$ & 0,522 \\
\hline 42 & $\begin{array}{l}\text { En la enseñanza de las ciencias naturales o de las ciencias sociales, las } \\
\text { explicaciones y los experimentos buscan demostrar los logros teóricos } \\
\text { elaborados por los profesionales de diferentes áreas del conocimiento. }\end{array}$ & 0,450 \\
\hline 48 & $\begin{array}{l}\text { Al enseñar, el profesor busca que sus estudiantes construyan } \\
\text { teorías que luego deben demostrar. }\end{array}$ & 0,409 \\
\hline 24 & $\begin{array}{l}\text { La historia de las teorías pedagógicas da cuenta de cómo, en diferentes épocas, } \\
\text { los docentes han sostenido o cambiado sus diferentes aplicaciones. }\end{array}$ & 0,343 \\
\hline 27 & Aprender significativamente no implica cambiar lo que ya se sabe. & 0,254 \\
\hline
\end{tabular}

Fuente: elaboración propia. 
El cuarto factor, con correlaciones moderadas, puede observarse por seis ítems, de los cuales cuatro se refieren a los principios de actuación acerca del profesor y su enseñanza constructivista. Desde los principios de actuación se comprende que, cuando enseña, persigue y logra un cambio conceptual, metodológico y axiológico en sus estudiantes. De igual forma, como se ha reiterado no son concepciones constructivistas absolutas sino relativas, tornándose en concepciones eclécticas; es decir, que se aceptan postulados acerca del aprendizaje, enseñanza y ciencia de tipo constructivistas y de tipo empiropositivista(s).

\section{Perspectiva comprensiva de las concepciones}

\section{Significados de las concepciones epistemológicas}

Se considera que las teorías implícitas "organizadoras de la práctica que posee cada enseñante, que orientan sus decisiones en la programación, la actuación en la clase o la evaluación, se las ha denominado 'concepciones"' (Hernández y Sancho, 1996, p. 168). Teniendo como base las afirmaciones precedentes, es posible interpretar los significados que los docentes universitarios tienen de sus prácticas pedagógicas; así, respecto a la tendencia epistemológica, se orienta hacia una concepción empiropositivista; si se revisa el concepto de ciencia, se concibe como un "conjunto de conocimientos organizados obtenidos mediante métodos definidos acerca de un objeto de estudio". Las concepciones adquieren forma de creencias o intuiciones o teorías implícitas que actúan de forma inconsciente en el profesorado (Valverde, 2012).

\section{Significados de las concepciones de enseñanza}

Respecto de lo conceptual de la categoría "aprender" se ubica en un punto intermedio; es decir, que se encuentra un elemento empiropositivista cuando se menciona a los docentes como tutores expertos y guías del estudiante; desde la postura constructivista, también se puede encontrar una expresión que concede al estudiante la posibilidad de aprender por sus propios medios cognitivos de manera reflexiva, consciente y significativa.

\section{Significados de las concepciones de aprendizaje}

En relación con el aprendizaje, existe una producción discursiva que, más allá de la verdad, la razón y la moral, gira en torno a nociones subjetivas, símbolos y creaciones de sí mismo, tal como lo manifestó Foucault (1998) en Voluntad de saber.

Respecto al aprendizaje, cuando se trata de interpretar algunas posturas teóricas de parte de los docentes participantes en la investigación, se encuentra algún rasgo empiropositivista al afirmar que el aprendizaje es "encontrar cosas o hechos desconocidos por parte del investigado". Por lo demás, las afirmaciones son de corte constructivista puesto que se consideran un "proceso de asimilación, adquisición y construcción del conocimiento". Otra reflexión surge al encontrar que el aprendizaje es concebido como "acción de apropiación de conocimiento, o como una "adquisición de conocimientos y saberes". En cuanto a la técnica, se encuentra una concepción empiropositivista, al mencionar que es un "procedimiento para lograr un objetivo" o un "procedimiento sistematizado para la obtención de un resultado”.

A diferencia de la enseñanza, en el aprendizaje, los docentes, por lo menos en lo que se refiere a la parte teórica, su pensamiento se orienta hacia el aprendizaje constructivista y muy poco en lo referente a un pensamiento empiropositivista.

Relaciones entre el significado de las concepciones

Se puede afirmar que la mayoría de las concepciones respecto de lo epistemológico se encuentra ubicado en lo empiropositivista; así, la concepción de ciencia, conocimiento, concepto, inclusive la de contexto, se ha expuesto en sus acepciones como empiropositivita. Respecto a las concepciones pedagógicas, las cosas cambian, porque la mayoría mantiene un trasfondo constructivista más que empiropositivista. En lo netamente constructivista, se encuentran las concepciones: aprender, didáctica, enseñanza y pedagogía. 


\section{Integración de las perspectivas descriptivas y comprensivas}

\section{Concepciones epistemológicas}

En las concepciones epistemológicas empiropositivistas se puede observar que hay una mayor inseguridad en el profesorado, en cuanto a rechazar o aceptar las ideas empiropositivistas en la enseñanza y aprendizaje de las ciencias. De igual manera, se muestra una tendencia muy baja a aceptar las posiciones empiropositivistas acerca de la forma como las teorías de las ciencias son obtenidas a partir de observaciones cuidadosas del mundo. Con una media con valor igual a 4 (en desacuerdo), se rechaza la idea empiropositivista de que el progreso científico se caracteriza por la continuidad y conservación de las ideas sobre el mundo.

Los hallazgos permiten evidenciar que, según las concepciones, los docentes mejor evaluados en sus instituciones desde la inferencia analítica se sienten inseguros de aceptar y rechazar las ideas o concepciones epistemológicas empiropositivistas o constructivistas. Además, desde la comprensión de los significados se encuentra algo similar; en tanto que, el profesorado tiene una marcada orientación empiropositivista, sin embargo, al conceptualizar los términos tienden hacia una postura constructivista porque atienden únicamente a la definición del término, el cual no es un reflejo de sus concepciones o sus creencias.

\section{Concepciones pedagógicas y didácticas}

Éstas se integran a partir del análisis cuantitativo, desde los resultados de las concepciones de enseñanza y aprendizaje empiropositivista y constructivista, mientras que, para lo cualitativo, se realiza desde la comprensión de los significados de los conceptos emitidos por el profesorado.

Ahora bien, con las concepciones de enseñanza constructivista, se puede establecer que existen cinco ítems con las puntuaciones de 2 (de acuerdo), lo que implica que en las creencias o tendencias del mejor profesorado universitario se acepta la enseñanza constructivista respecto a que se debe procurar que el estudiante contraste los significados elaborados y que el mejor profesor es el que logra cambios significativos.

Así mismo, respecto de las concepciones del aprendizaje empiropositivista, se puede observar que son cinco las creencias o tendencias relativas, como: el estudiante demuestra el aprendizaje por repetición; el aprendizaje es una acumulación de información; aprender es aceptar verdades absolutas; el estudiante demuestra que ha aprendido cuando reproduce lo que el profesor repite, y el aprendizaje es independiente de la enseñanza. Creencias que alcanzan una media con un valor aproximado a 4 (en desacuerdo), lo que indica que el profesorado rechaza estas ideas de aprendizaje empiropositivistas de las ciencias. De igual manera, se muestra inseguridad (media de 3 ) hacia la creencia o posición del aprendizaje empiropositivista de que aprender significativamente no implica cambiar lo que ya se sabe.

\section{Aprendizaje constructivista}

Siguiendo con este pensamiento relativo a las concepciones del aprendizaje constructivista, se puede analizar cómo la gran mayoría de los ítems tienen puntuaciones de 2 (de acuerdo), lo cual implica que, desde las creencias o tendencias o posiciones, se acepta el aprendizaje constructivista respecto a que todo aprendizaje lo es, en la medida de que los estudiantes elaboren el significado propio.

De igual manera, se mantiene una concepción de aprendizaje con enfoque constructivista al interpretar la concepción de la comprensión, cuando se lo refiere a la "acción de adquirir o asimilar conocimiento para ser aplicado en la realidad", o también como la "capacidad del ser humano para interiorizar un concepto". En igual inclinación se encuentra la concepción constructivista en relación con el descubrimiento, considerado conocimiento de algo nuevo. Todas estas concepciones se afianzan en Ausubel, Novak y Hanesian (1996), desde su teoría sobre el aprendizaje significativo, el cual, por recepción, involucra la adquisición de nuevos significados. 
Las reflexiones efectuadas acerca de la enseñanza y el aprendizaje desde lo cuantitativo y cualitativo que se han realizado, al interpretar el pensamiento docente, muestran de manera clara que las concepciones sobre los significados de la didáctica se orientan de notoriamente en lo constructivista.

Esto permite involucrar la adquisición de significados nuevos por parte del estudiante, quien requiere tanto de una actitud de aprendizaje significativo como de la presentación de algún material potencialmente significativo. En este contexto se ubica la concepción de pedagogía dada por los docentes con visión constructivista; se afirma, entonces, que el estudiante es el autor de su propio conocimiento (Marroquín, 2015). Además, se concibe la pedagogía como "la ciencia orientada al estudio de la educación como proceso de enseñanza y aprendizaje de los individuos" y como el "conjunto de estrategias y métodos orientados a la formación del ser humano para la solución de problemas". Así, se puede concluir que las concepciones pedagógicas son de corte constructivista.

En la interpretación de las concepciones sobre didáctica y enseñanza, se menciona que son métodos y técnicas para mejorar el proceso enseñanza y aprendizaje. De igual forma, es concebida como "una disciplina que brinda técnicas, métodos y estrategias para desarrollar el proceso enseñanza y aprendizaje". Cabe mencionar a Pérez, Mateos, Scheuer y Martín (2006), quienes analizan cuáles son y qué función cumplen las concepciones de profesores y alumnos sobre los procesos de enseñanza y aprendizaje, o de forma más general, las creencias sobre la mente de los aprendices y el conocimiento. Entre las concepciones de enseñanza y aprendizaje, se cuenta con aportes orientados de manera más enfática hacia las concepciones de tipo constructivista, con algunos matices sobre metacognición (Mayor, Suengas y González, 1993), teoría de los modelos mentales (Corral y Asencio, 2016, citado por Carretero y Asensio, 2016), creencias epistemológicas, fenomenografía, teorías implícitas y perfil del docente y análisis de la práctica.

En consecuencia, el análisis inferencial y la comprensión de los significados, desde el ámbito pedagógico y didáctico, tienden hacia el pensamiento constructivista.

\section{Hacia una propuesta de formación docente desde los resultados obtenidos en la investigación}

Esta propuesta de formación se puede estudiar y complementar desde la identidad institucional y trabajar con sus expertos educadores profesionales, para que fortalezcan la forma de pensar, actuar y sentir del profesor universitario. Se caracteriza porque fortalece el desarrollo profesional del profesorado, se centra en la práctica como referencia, enriquece el trabajo del profesorado experimentado y motiva al profesorado novel.

Tabla 15. Propuesta de formación docente

\begin{tabular}{|c|c|c|c|}
\hline No. & $\begin{array}{l}\text { Unidades } \\
\text { didácticas }\end{array}$ & Competencia a alcanzar & Temario \\
\hline 1 & Epistemología & $\begin{array}{l}\text { Reconoce e identifica los } \\
\text { enfoques epistemológicos } \\
\text { constructivistas y su impacto } \\
\text { en la educación del siglo xxl. }\end{array}$ & $\begin{array}{l}\text { 1.1. Enfoques epistemológicos. } \\
\text { 1.2. Diferenciación del enfoque empiropositivista } \\
\text { del enfoque constructivista. } \\
\text { 1.3. Impactos de la epistemología } \\
\text { en la educación del siglo xx.. }\end{array}$ \\
\hline 2 & Enseñanza & $\begin{array}{l}\text { Reconoce e identifica la } \\
\text { enseñanza y la didáctica } \\
\text { desde el cognitivismo hasta } \\
\text { el constructivismo. }\end{array}$ & $\begin{array}{l}\text { 2.1. Enfoques de enseñanza } \\
\text { 2.2. Revolución cognitiva. } \\
\text { 2.3. Diferenciación de la enseñanza empiropositivista } \\
\text { de la enseñanza constructivista. } \\
\text { 2.4. Didáctica o estrategias de aprendizaje. }\end{array}$ \\
\hline
\end{tabular}




\begin{tabular}{|c|c|c|c|}
\hline No. & $\begin{array}{l}\text { Unidades } \\
\text { didácticas }\end{array}$ & Competencia a alcanzar & Temario \\
\hline 3 & Aprendizaje & $\begin{array}{l}\text { Reconoce e identifica las teorías } \\
\text { del aprendizaje, la formación } \\
\text { del profesorado, y el proceso } \\
\text { de aprendizaje y de docencia } \\
\text { del profesor universitario. }\end{array}$ & $\begin{array}{l}\text { 3.1. Teorías del aprendizaje. } \\
\text { 3.2. Diferenciación del aprendizaje empiropositivista } \\
\text { del aprendizaje constructivista. } \\
\text { 3.3. Formación del profesorado. } \\
\text { 3.4. Proceso de aprendizaje y de docencia del profesor. }\end{array}$ \\
\hline
\end{tabular}

Fuente: elaboración propia.

\section{Discusión}

El propósito fundamental de la investigación fue explorar lo que se mantiene y se cambia en las concepciones epistemológicas, pedagógicas y didácticas, que subyacen en las mejores prácticas pedagógicas del profesorado universitario para fortalecer una propuesta de formación permanente. Se evidencia que las teorías personales e implícitas como principios de actuación mutaron de las concepciones de enseñanza y aprendizaje empiropositivistas a las concepciones constructivistas; sin embargo, hay inseguridad en aceptar o rechazar los principios de actuación o teorías personales de uso de las concepciones epistemológicas empiropositivistas, para lo cual se requiere un proceso de formación permanente para reconstruir los saberes epistemológicos, caracterizarlos, diferenciarlos y asumir posturas críticas relevantes y significativas con esta categoría de análisis.

Es pertinente hacer las siguientes preguntas: ¿Las concepciones epistemológicas, pedagógicas y didácticas tienen una sola orientación?, ¿un solo pensamiento? Intentando dar respuesta, una vez analizados los resultados, se encuentra que las concepciones tratan de mostrar una postura definida entre los docentes participantes en la investigación, pero acudiendo a los significados de lo epistemológico, pedagógico y didáctico; las concepciones epistemológicas empiropositivistas se han aceptado en gran mayoría porque las evidencian como propiedad en su pensamiento; sin embargo, no se puede afirmar que sus concepciones están en una sola significación, porque además lo constructivista ocupa también su lugar en las concepciones del profesorado, sobre todo en lo relativo a la enseñanza y el aprendizaje. Entonces, la respuesta a la pregunta inicial sería negativa, al haber realizado el análisis y la interpretación acorde con un paradigma mixto; con estos dos enfoques, se ha comprobado el pensamiento docente $y$, al apoyarse en ellos, se afirma lo que se ha comprobado.

A lo mejor, se esperaba que las concepciones del mejor profesor de las instituciones participantes que pueden hacerse a una práctica más orientada, a ceder espacios a los estudiantes como artífices de su aprendizaje, no se puede afirmar categóricamente puesto que se mantienen en algunas ideas o posturas epistemológicas empiropositivistas; sin embargo, los resultados indican que sus concepciones acerca de enseñanza y aprendizaje son de tipo constructivista. Pero, no se asevera de manera taxativa, porque a diferencia de las concepciones epistemológicas, las concepciones pedagógicas y didácticas se ubican en el extremo opuesto; es decir, muestran un enfoque constructivista que permite concluir que ciertos términos fueron analizados más desde el significado que desde su práctica. Ortega y Gasset (1986), en su obra Ideas y creencias, afirma que las creencias establecen el modo de ser de las personas. Las ideas en cambio son analizadas, pensadas, categorizadas, utilizadas; ellas sirven para resolver problemas; son abstractas; son herramientas que ayudan a explicar el universo. Esto es lo que se ha encontrado en la investigación y, de cierta manera, ayuda a comprender que los docentes siendo empiropositivistas 
en sus creencias, sean constructivistas en el modo de explicar el significado de los términos con una postura constructivista.

Así, por la falta de formación de los maestros, la influencia de las concepciones empiropositivistas de los autores de las reformas educativas y la falta de programas de formación pedagógica con enfoque constructivista en las instituciones, cuándo se podrá esperar que el conocimiento pedagógico orientado hacia la actividad del educando se imponga y no un conocimiento pedagógico y didáctico, que se ubique más en lo tradicional, puesto que, pedagogos de las últimas décadas como Ausubel, pregonero del aprendizaje significativo, no encuentre el eco esperado. Las bases teóricas están en relación directa con el objeto de estudio, impregnadas desde Piaget, Ausubel, Vygotsky; en lo pedagógico, desde Beltrán (1998), Beltrán y Genovard (1998) y Monereo et al. (2006), al igual que son relevantes los aportes de Zuleta, Rodari, Pennac y, sin dudas, de Foucault. El pensamiento, el conocimiento y la práctica del profesorado se mueven alrededor del develamiento de los supuestos epistemológicos, pedagógicos y didácticos, que subyacen de los principios de acción de las prácticas pedagógicas.

Ahora bien, en los hallazgos de la investigación se hizo una consideración importante que, en este momento, abre el abanico de concepciones para enriquecerlas más que para reducirlas o meramente referenciarlas. Para abarcar todos los elementos afectivo-emocionales, cognitivos y socioculturales o contextuales que están en juego en el término concepción, estos pueden ser incluidos. Entonces, las concepciones epistemológicas, pedagógicas y didácticas se pueden entender como principios orientadores de la práctica o principios de actuación en uso por el docente como poseedor de unas posturas o ideas (Gallego y Pérez, 1999; Hernández y Sancho, 1996; Prieto, 2007; Perafán, 2015). Tal y como se lo ha considerado, constituye un texto de naturaleza psicosocial que permite entender y explicar el fenómeno de ver, pensar y sentir el mundo que nos rodea de forma simultánea. Se trataría de integrar en un único elemento a estos complejos referentes (Buendía, Carmona, González y López, 2012).
En los resultados se dijo que, desde esas teorías de uso y observables a través de las respuestas dadas, el profesorado tiene inseguridad en rechazar o aceptar las ideas de enseñanza empiropositivistas de las ciencias; de igual manera, se muestra una tendencia muy baja a aceptar (media de 2) las posiciones de enseñanza empiropositivistas. Sin embargo, se aceptan las concepciones constructivistas de enseñanza respecto a que se debe procurar que el estudiante contraste los significados elaborados; que, al enseñar, haya un cambio conceptual, metodológico, actitudinal y axiológico; que enseñar es generar el ámbito pedagógico y didáctico para lograr experiencias de aprendizaje. Las respuestas dadas expresan las teorías personales o en uso o principios de actuación (Gallego y Pérez, 1999; Prieto, 2007; Perafán, 2015) del profesorado acerca de su didáctica.

Así mismo, desde las creencias o teorías personales o teorías implícitas que el profesorado tiene acerca del aprendizaje empiropositivista, se rechaza que el estudiante demuestre el aprendizaje por repetición; que el aprendizaje es una acumulación de información; que aprender es aceptar verdades absolutas; que el estudiante demuestra que ha aprendido cuando reproduce lo que el profesor repite, y que el aprendizaje es independiente de la enseñanza. Estos principios de acción o de teorías de uso personal indican que el aprendizaje no es mecanicista, y más bien se aceptan otras perspectivas, entre las cuales está el aprendizaje constructivista, en cuanto a que todo aprendizaje lo es, en la medida de que los estudiantes elaboren el significado; que aprender es transformar aquellas explicaciones que ya se posee; que en el proceso de aprendizaje el estudiante construye conscientemente nuevos significados; que el aprendizaje es acompañado y en permanente autoevaluación, que se apoya en sus fortalezas y corrige errores; que los estudiantes utilizan su saber previo para apropiarse de las nuevas temáticas de sus profesores, y que el estudiante utiliza su pensamiento autónomo y divergente en la mejora de sus aprendizajes. 
En este sentido, las teorías en uso o principios de actuación o teorías personales acerca del aprendizaje, coinciden en gran medida con la concepción de Beltrán y Genovard (1998), cuando afirman que el aprendizaje "es en realidad la huella del pensamiento; se podría afirmar que la calidad del aprendizaje pasa, no tanto por la calidad de las actividades del profesor, como por la calidad de las acciones del estudiante" (p. 394).

Cabe pensar que el profesorado asume en sus teorías personales, pocas ideas epistemológicas constructivistas como el rol o tarea que tienen los hombres y mujeres de ciencias, al construir conocimiento o teorías acerca de la realidad, la importancia de aprender a partir de lo que ya se sabe y de la comprensión de las teorías de las ciencias como tramados significativos de conceptos, y que el ámbito pedagógico y didáctico es vital para enseñar y generar experiencias de aprendizaje.

Todo lo anterior parece ratificar que el mejor profesor de las universidades asume en sus teorías de uso o teorías personales, unas concepciones pedagógicas y didácticas de naturaleza constructivista, muy pocos principios de actuación de ideas epistemológicas constructivistas. Sin embargo, mantiene en sus principios de actuación o teorías de uso algunas estrategias didácticas de tipo empiropositivista que se enfatiza en la observación, explicación y conclusión acerca de algunos fenómenos, en que los estudiantes descubren el conocimiento, en que las teorías de la ciencia o teorías científicas son fruto de observaciones cuidadosas y de procesos deductivo-inductivos. Por todo ello, en los saberes implícitos del mejor profesorado universitario de Colombia, basados en la experiencia acumulada o creencias como estrategias didácticas o principios de actuación, se expresa una diferencia clara entre las concepciones de aprendizaje, enseñanza y ciencia de tipo constructivistas de las concepciones de tipo empiropositivistas, pero sin despojarse totalmente de ellas, en particular de las concepciones epistemológicas empiropositivistas y de algunas concepciones de enseñanza.
Se considera que los hallazgos de este estudio son novedosos, en comparación con otras investigaciones, particularmente, las de Gallego y Pérez (1999) y Valverde (2001), aunque de los estudios de los autores mencionados se utilizan instrumentos de recolección similares, pero con una forma de análisis y presentación de resultados diferente. Se puede expresar, además, que aún existen posturas eclécticas y muy pocas a lo encontrado en los estudios de referencia, las cuales están centradas en las concepciones epistemológicas y las concepciones de enseñanza, donde se identifican posturas empiropositivistas y constructivistas. De esta forma, se constata que aún falta teorización y comprensión del fundamento epistemológico a nivel de las ciencias en general y particular. $\mathrm{Al}$ respecto, en el estudio de Gallego y Pérez (1999), se concluye que a "pesar de que, en las pruebas tipo Likert, las semánticas, las de composición y la de elaboración de mapas conceptuales, los resultados hablan a favor de un posicionamiento constructivista. Se confirma un eclecticismo" (Gallego y Pérez, 1999, p. 279). Al respecto de esta afirmación se debe decir que es muy cierto que las aplicaciones de los dos instrumentos no evidencian unos principios de acción estrictamente constructivistas sino algunos principios de actuación ecléctica en dichas concepciones epistemológicas y de enseñanza, no así en las de aprendizaje que enfatizan un posicionamiento constructivista.

Como se ve, aunque el posicionamiento es aparente en las concepciones de constructivistas, los principios de actuación del mejor profesorado de las universidades acreditadas de Colombia, se posicionan en teorías implícitas de uso o principios de actuación en el aprendizaje y en algunas en las concepciones de enseñanza. Sin embargo, su evidencia está dada más por las respuestas al ítem, asumidos por lo profesores como estrategias didácticas (Prieto, 2007), lo cual permite afirmar que los principios de actuación constructivistas se manifiestan en las estrategias de enseñanza y aprendizaje. A pesar de que ninguno de los estudios realizados y estudios de referencia han efectuado el análisis factorial, se entrevé la validez de constructo por haber encontrado otra forma de agrupar los ítems, dándole relevancia a las teorías de actuación 
ecléctica constructivistas o empiropositivistas de la ciencia, el aprendizaje y la enseñanza; las concepciones empiropositivistas cerca del aprendizaje, la enseñanza y la ciencia; las concepciones constructivistas acerca de los hombres y mujeres de ciencias, de los mejores estudiantes y profesores, $\mathrm{y}$ las concepciones constructivistas acerca del mejor profesor y su enseñanza; que reconoce, en buena medida, lo que los estudios han destacado en aceptar una postura ecléctica de las concepciones, aunque enfatizando sus principios de actuación en las concepciones constructivistas acerca del aprendizaje, de los hombres y mujeres de ciencias, del mejor profesor y su enseñanza.

\section{Conclusiones}

Se puede afirmar que en el grupo profesoral participante de las IEs que libremente formaron parte de esta investigación, según el análisis de los cuatro nuevos factores, se mantienen las concepciones eclécticas de aprendizaje, enseñanza y ciencia, y las concepciones empiropositivistas de aprendizaje, enseñanza y ciencia.

Respecto a las concepciones pedagógicas y didácticas que subyacen en la significación de sus prácticas de enseñanza, se evidencia que son de carácter ecléctico asumiendo, los docentes, posturas intermedias.

Desde lo cualitativo, desde el significado de las concepciones didácticas desde el aprendizaje, la docencia y las demás concepciones que involucran la actividad de los dos actores del hecho de aprender, se descubre un acendrado enfoque constructivista.

Desde lo comprensivo o hermenéutico, las concepciones pedagógicas y didácticas se ubican en extremos opuestos, es decir, muestran un enfoque constructivista que permite concluir que ciertos términos fueron analizados más desde el significado que desde su práctica.

\section{Referencias}

Ausubel, D., Novak, J. y Hanesian, H. (1996). Psicología educativa. Un punto de vista cognoscitivo. México: Trillas.

Bain, K. (2007). Lo que hacen los mejores profesores universitarios. Valencia: Publicaciones Universitat de València.

Beltrán, J. (1998). Procesos, estrategias y técnicas de aprendizaje. Madrid: Síntesis, S.A.

Beltrán, J. y Genovard, C. (1998). Psicología de la instrucción I: variables y procesos básicos. Madrid: Síntesis S.A.

Buendía, E., Carmona, M., González, D. y López, R. (2012). Concepciones de los profesores de educación secundaria sobre evaluación. Educación XX1, 2, 126-153.

Carretero, M. y Asensio, M. (2016). Psicología del pensamiento ( ${ }^{\circ}$ ed.).Madrid: Alianza Editorial.

Foucault, M. (1982). Hermenéutica del sujeto: Madrid: Ediciones Akal.

Foucault, M. (1998). Voluntad del saber. México: Siglo XxI.

Gallego, R. y Pérez, R. (1999). El problema del cambio en las concepciones epistemológicas, pedagógicas y didácticas. Bogotá: Universidad Pedagógica Nacional.

González, M. y Ospina H. (2014). El planteamiento metodológico en una indagación sobre el saber pedagógico de profesores universitarios. Hallazgos, 11(22). Recuperado de http://www.scielo.org.co/scielo.php?script=sci_ arttext\&pid=S1794-38412014000200016\&lng=es\&n $\mathrm{rm}=\mathrm{iso} \& \operatorname{lng}=\mathrm{es}$

Hernández, F. y Sancho, J. (1996). Para enseñar no basta con saber la asignatura. Barcelona: Papeles de Pedagogía, Paidós.

Marroquín, M. (2015). Docentes estratégicos forman estudiantes estratégicos. Una propuesta para el trabajo de aula. San Juan de Pasto, Colombia: Editorial Publicaciones UNIMAR.

Mayor, J., Suengas, A. y González, J. (1993). Estrategias metacognitivas. Aprender a aprender y aprender a pensar. Madrid: Editorial Síntesis, S. A.

Monereo, C., Castelló, C., Clariana, M., Palma, M. y Pérez, M. (2006). Estrategias de enseñanza y aprendizaje. Formación del profesorado y aplicación en la escuela. Barcelona: Editorial Graó. 
Monereo, C., Badia, A., Bilbao, G., Cerrato, M. y Weise, C. (2009). Ser un docente estratégico: cuando cambiar la estrategia no basta. Recuperado de https://es.scribd. com/.../Monereo-C-Badia-a-Bilbao-G-Cerrato-M$\mathrm{y}$-Weise-C-2009

Ortega y Gasset, J. (1986). Ideas y creencias (y otros ensayos de filosofía). Madrid: Alianza.

Pennac, D. (1994). Mal de escuela. Barcelona: Mondadori.

Perafán, A. (2015). Conocimiento profesional docente y prácticas pedagógicas: el profesorado como productor de conocimiento disciplinar-profesional. 1a. ed. Bogotá: Editorial Aula Humanidades.

Pérez, M., Mateos, M., Scheuer, N. y Martín, E. (2006). Nuevas formas de pensar la enseñanza y el aprendizaje. Las concepciones de profesores y alumnos. Barcelona: Editorial Graó.

Pozo, J. (1997). Teorías cognitivas del aprendizaje (5ta. Ed.). Madrid: Morata.
Pozo, J., Scheure, N., Puy, M., Mateos, M., Martín, E. y De la Cruz, M. (2006). Nuevas formas de pensar la enseñanza y el aprendizaje. Barcelona: Graó.

Prieto, L. (2007). Autoeficacia del profesor universitario. Eficacia percibida y práctica docente. Madrid: Narcea.

Rodari, G. (2008). Gramática de la fantasía: introducción al arte de inventar historias. Buenos Aires: Colihue.

Valverde, O. (2001). El problema del cambio en el pensamiento del profesor(a) de sus teorías implícitas: epistemológicas, pedagógicas y didácticas. Tesina: Universidad de Valencia.

Valverde, O. (2012). Las creencias de autoeficiencia en la práctica pedagógica del docente universitario. Pasto: Editorial UNIMAR.

Zuleta, E. (2005). Elogio de la dificultad y otros ensayos. Medellín: Fundación Estanislao Zuleta. 